\title{
UNIVERSITYOF
}

FORWARD

THINKING

WESTMINSTER用

WestminsterResearch

http://www.westminster.ac.uk/westminsterresearch

CODEX: mapping co-created data for speculative geographies

Corby, T., Baily, G. and Sabbata, S

This is a copy of the final accepted version of an article published in Leonardo in 2016.

(c) 2016 ISAST

The online edition of the article is available at:

https://dx.doi.org/10.1162/LEON a 01347

The WestminsterResearch online digital archive at the University of Westminster aims to make the research output of the University available to a wider audience. Copyright and Moral Rights remain with the authors and/or copyright owners.

Whilst further distribution of specific materials from within this archive is forbidden, you may freely distribute the URL of WestminsterResearch: ((http://westminsterresearch.wmin.ac.uk/)).

In case of abuse or copyright appearing without permission e-mail repository@westminster.ac.uk 


\section{CODEX: MAPPING CO-CREATED DATA FOR SPECULATIVE GEOGRAPHIES}

Tom Corby, Gavin Baily (University of Westminster), Dr Stefano de Sabbata (University of Leicester).

Email:<corbyt@wmin.ac.uk>, <gavin@baily.net>, University of Westminster, London, W1W 6UW, UK. E-

mail:<s.desabbata@le.ac.uk>, University of Leicester, LE1 $7 \mathrm{RH}, \mathrm{UK}$.

See $<$ www.mitpressjournals.org/toc/leon/XX/X $>$ for supplemental files associated with this issue. $<$ Editor will fill in the $X$ ' $s>$

\section{Submitted: <leave for Editor to date>}

\section{Abstract}

This paper discusses a series of artworks named CODEX produced by the authors as part of a collaborative research project between the Centre for Research in Education, Art and Media (CREAM), University of Westminster, and the Oxford Internet Institute. Taking the form of experimental maps, large-scale installations and prints, we show how big data can be employed to reflect upon social phenomena through the formulation of critical, aesthetic and speculative geographies.

Discourses around big data promise fundamental changes in our ability to represent and understand human behavior (1). Analysis of digital archives generated from user interactions with Blogs, Wikipedia. Flickr, Twitter etc. (termed 'big social data') enable distinctive new ways of capturing the social as flows of sentiment, idea and debate (2). Advocates argue that the patterns revealed in these datasets have the potential to reveal solutions to some of our most pressing social, economic, political, and environmental issues (3)

Affect and an interest in the social are also intrinsic themes for contemporary arts practice (4) which would seem to promise a fit to art practices concerned with representing social realities. Just as documentary forms arising from photography and film have variously sought to image social actuality through

Fig. 1. CODEX Global, Lenticular Projection data print, Wikipedia language edits from a 12-year period (C) Gavin Baily, Tom Corby)

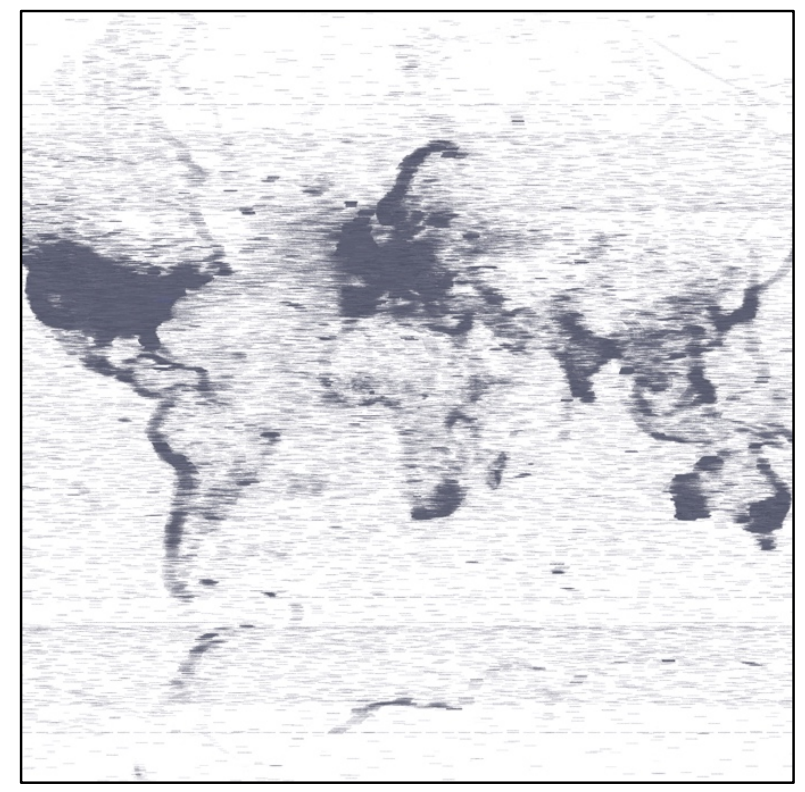

creative modes tied to their technological affordances, we hypothesize that data-driven approaches appear to offer new ways to represent the real through the ways they capture social practices.

\section{CODEX}

CODEX consists of a number of animations displayed in installation format, and large-scale inkjet prints derived from a geographic mapping of Wikipedia's language edition articles that refer to locations, countries and cities (5). This uses geocoded Wikipedia data generated using Wikimedia Tool Labs which provide access to replicas of Wikimedia databases, and an environment for scripting queries. The project brings together expertise in digital art practice (Corby, Baily), specialist programming and geographic visualization (Baily) and quantitative human geography and big data analysis (De Sabbata).

The project follows in a history of artistic and philosophical cartographic interventions, such as Agnes Denes' map projections (6), which relocate scientific and technological

knowledge toward an aesthetic reimagining of humanity's relationship to the earth, or Buckminster Fuller's Dymaxion maps (7) which develop a similar ecological argument through speculative geographies. Working from this critical and aesthetic tradition, but with a contemporary focus on data and algorithmic sorting, CODEX explores how a given socially constructed dataset enables us to visualise how the dispersal of online knowledge (and thus of power in a Foucauldian sense) reflects imbalances in political and geographic power in the world (8, 9).

Article titles derived from this data are used to image glyphs and phonemes that hint at the underlying content and structure of the data as fields of partial visual texts. The prints and animations, show how en masse, Wikipedia contributions represent collective activity and shared bodies of knowledge. The metadata associated with each article, pictures which locations are most edited and revised, which are the longest, and which are translated into other languages; often an indication that these coded spaces are contested and fought over much as real space. This can be seen both in the frequency of article revisions related to pages referencing controversies, and also the geographic distribution of articles along boundaries of strong cultural identities, e.g. Spain and Eastern Europe.

In the prints (Fig.1) and animations (Fig.2), the collective structures of the encyclopedia are made tangible scaling text fragments in relation to the number of times an article has been edited. The effect of this is a differential texturing across the map, where major articles appear as large-scale labels and less developed but more abundant articles form topographies of varying density and in some cases phlegm-like viscosity. In the prints this shows as layered, scabrous and inked surfaces that have a three-dimensional quality similar to geological forms (Fig.3). The temporal development of article distribution on Wikipedia can be gleaned by looking at the creation dates of the articles. The animations of this editing activity describe geographic spaces and how each language community has developed and grown at different times and rhythms.

Alongside and in conjunction with the artworks, we developed a software toolkit under a GNU General Public License (10), to enable other artists and creative practitioners to generate visual output of large-scale socio-geographic datasets. The toolkit is authored in Python, and built using a number of GIS 


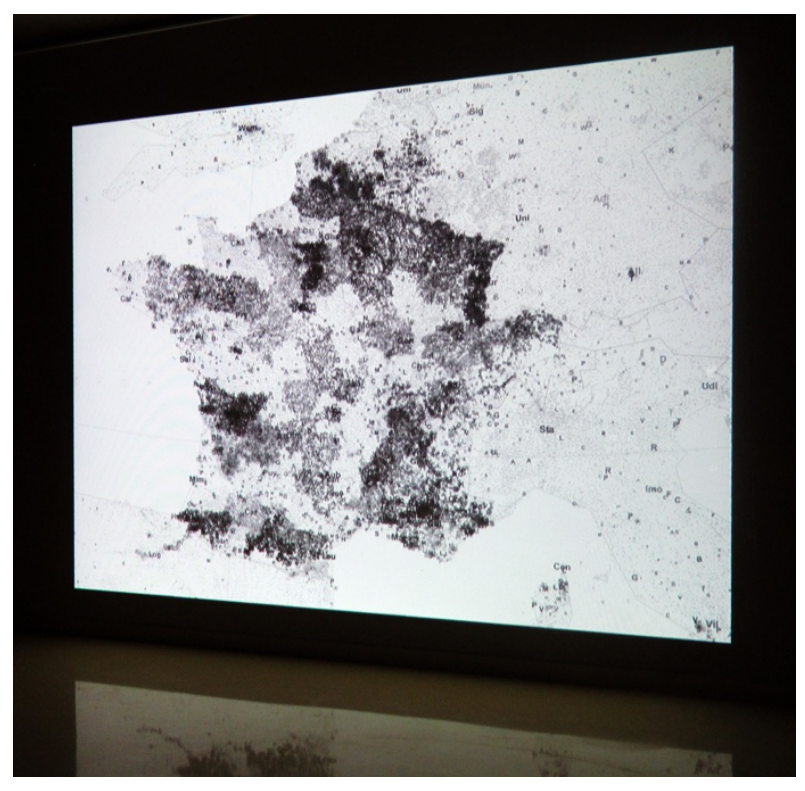

Fig. 2. CODEX Europe (2014), installation animating Wikipedia language edits from a 12-year period,

libraries and the PySide Qt framework. We have used the toolkit to render the human activity that generates archives of geo-coded social media, Wikipedia articles, and Open Street Map exports. The toolkit is designed to enable the output of large-scale map images and geographic animations, and can be employed to explore and interact with the datasets, configuring how the maps are rendered.

\section{Discussion}

If Agnes Denes and Buckminster Fuller's works hints at the 'utopian' or redemptive power of reason and a human capacity to progress to a saner more ecologically and socially equitable future, the mappings revealed in CODEX present a less certain vision. The deformations imaged in the work draw attention to how speculative aesthetic and critical data mappings using material (experimental prints) and temporal expressions (animations), can show how excessive and flows of capital, technology, and material are reshaping geography, space and time, thereby inviting us to contemplate our role in a world in upheaval. Additionally, by demonstrating the discrepancy in use of social media platforms between geographic areas of the Global South and Global North, we show how objective conventions of space, knowledge and data representation in online platforms are inflected by political and social power structures that mirror power distributions in the real world. In doing so CODEX aligns itself with recent work in social analytics, Tufekci (11), for example has noted that claims for validity and ultimately veracity of representation in big data analysis of social phenomena are undermined by an unevenness of coverage and access to technology and similarly CODEX asks (and partly answers): who is represented, and who is left out of the picture?

\section{Acknowledgements}

We thank the UK Arts and Humanities Research Council (AHRC) for funding this research, Professor Mark Graham from the Oxford Internet Institute, University of Oxford for providing encouragement and support, and colleagues at the Centre for Research in Education, Art and Media (CREAM), University of Westminster for their feedback and collegiality.

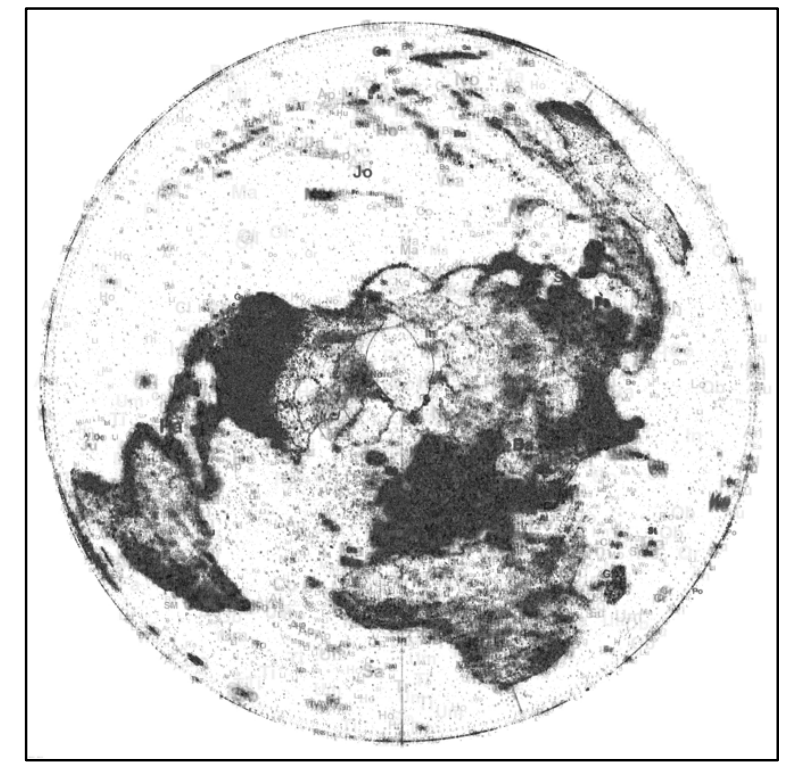

Fig.3. CODEX Globe (2015), inkjet on paper, $1219 \times 1219$ $\mathrm{mm}$, rendering Wikipedia language edits from a 12-year period (C) Gavin Baily, Tom Corby)

\section{References and Notes}

1. Rob Kitchin, "Big data and human geography Opportunities, challenges and risks," in Dialogues in Human Geography, Vol.3, No.3, (2013), pp.262-267.

2. Adam D. Kramer, Jamie E. Guillory, and Jeffrey T. Hancock, "Experimental evidence of massive-scale emotional contagion through social networks," in Proceedings of the National Academy of Sciences, (2014).

3. Viktor Mayer-Schönberger, and Kenneth Cukier, (2013). Big data: a revolution that will transform how we live, work and think (London: John Murray 2013).

4. T. J. Demos, "The politics of sustainability: contemporary art and ecology," in Radical Nature: Art and Architecture for a Changing Planet 1969-2009, F. Manacorda ed., exh. cat. (London: Barbican Art Gallery, 2009), pp. 16-30.

5. Further documentation and technical descriptions can be found at the project website: <digital-realism.net/>.

6. A. Denes, exh. dat. (Cornell University, Ithaca, New York: Herbert F. Johnson Museum of Art, 1992).

7. Buckminster Fuller, in "Life Presents R. Buckminster Fuller's Dymaxion World," in LIFE, (March 1943), pp. 41-55.

8. Our thanks to Dr Peg Rawes, University College London, who has helped in form our thinking behind the links between our work and that of earlier art historical and theoretical traditions. See for example: Peg Rawes,"Architectural Ecologies \& Ratios," in Bartlett International Lecture Series 2015/16, Bartlett School of Architecture, University College London, <vimeo.com/147110283> (2015).

9. See also the work of Mark Graham, Stefano de Sabbata and Matthew Zook from the Oxford Internet Institute who from a social science perspective have explored similar issues: "Towards a study of information geographies: (im)mutable augmentations and a mapping of the geographies of information," in Geo: Geography and Environment, Vol.2, Issue 1, (January-June 2015), pp. 88-105.

10. The GNU toolkit can be found at the project website: <digital-realism.net/2015/06/10/visualisation-toolkit/>.

11. Zeynep Tufekci, "Big questions for social media big data: Representativeness, validity and other methodological pitfalls," in ICWSM '14: Proceedings of the 8th International AAAI Conference on Weblogs and Social Media, (2014). 